OPEN ACCESS

Edited by:

Josh Huang,

Watson School of Biological

Sciences, United States

Reviewed by: Daniel W. Wesson, University of Florida, United States Kasia M. Bieszczad,

Rutgers University, The State University of New Jersey,

United States

*Correspondence:

Chengyu T. Li tonylicy@ion.ac.cn

Received: 29 April 2017 Accepted: 30 January 2018 Published: 13 February 2018

Citation: Han Z, Zhang $X$, Zhu J, Chen Y and Li CT (2018) High-Throughput Automatic Training System for Odor-Based Learned Behaviors in Head-Fixed Mice.

Front. Neural Circuits 12:15. doi: 10.3389/fncir.2018.00015

\section{High-Throughput Automatic Training System for Odor-Based Learned Behaviors in Head-Fixed Mice}

\author{
Zhe Han ${ }^{1,2}$, Xiaoxing Zhang ${ }^{1}$, Jia Zhu ${ }^{1,2}$, Yulei Chen ${ }^{1}$ and Chengyu T. Li ${ }^{1 *}$ \\ 'State Key Laboratory of Neuroscience, Key Laboratory of Primate Neurobiology, Institute of Neuroscience, CAS Center \\ for Excellence in Brain Science and Intelligence Technology, Chinese Academy of Sciences, Shanghai, China, ${ }^{2}$ School of \\ Future Technology, University of Chinese Academy of Sciences, Beijing, China
}

Understanding neuronal mechanisms of learned behaviors requires efficient behavioral assays. We designed a high-throughput automatic training system (HATS) for olfactory behaviors in head-fixed mice. The hardware and software were constructed to enable automatic training with minimal human intervention. The integrated system was composed of customized 3D-printing supporting components, an odor-delivery unit with fast response, Arduino based hardware-controlling and data-acquisition unit. Furthermore, the customized software was designed to enable automatic training in all training phases, including lick-teaching, shaping and learning. Using HATS, we trained mice to perform delayed non-match to sample (DNMS), delayed paired association (DPA), Go/No-go (GNG), and GNG reversal tasks. These tasks probed cognitive functions including sensory discrimination, working memory, decision making and cognitive flexibility. Mice reached stable levels of performance within several days in the tasks. HATS enabled an experimenter to train eight mice simultaneously, therefore greatly enhanced the experimental efficiency. Combined with causal perturbation and activity recording techniques, HATS can greatly facilitate our understanding of the neural-circuitry mechanisms underlying learned behaviors.

\section{Keywords: cognitive behavior, automatic training, head-fixed mice, working memory, olfaction}

\section{INTRODUCTION}

Behavioral design and analysis are critical for understanding neural mechanism of cognition (Gomez-Marin et al., 2014), including working memory (Fuster, 1997; Baddeley, 2012), decision making (Gold and Shadlen, 2007; Lee et al., 2012), and reversal of learnt rules (Bunge and Wallis, 2008). Combined with novel neural-circuitry technologies, such as optogenetics (Fenno et al., 2011), chemogenetics (Armbruster et al., 2007) and imaging methods (Deisseroth and Schnitzer, 2013), well-disigned behavioral paradigms can greatly facilitate the ciruitry level understanding of behaivor. Reliable behavioral paradigms are also useful in pre-clinic studies such as target identification and mechanistic studies for brain diseases (Götz and Ittner, 2008; Nestler and Hyman, 2010; Fernando and Robbins, 2011).

Optimally, behavioral training systems should be automatic, ready to scale up, blind in design, and flexible in changing paradigms. Automatic training systems (Schaefer and Claridge-Chang, 2012) met well with these criteria. There was a long history of designing automatic behaviortraining systems, for example in studies of operant conditioning (e.g., Davidson et al., 1971). Automatic training systems are composed of monitoring and feedback controlling of behavior. 
In free-moving mice, automatic measurement has been implemented in characterizing visual performance (de Visser et al., 2005; Benkner et al., 2013; Kretschmer et al., 2013), evaluation of pain sensitivity (Kazdoba et al., 2007; Roughan et al., 2009), freezing behavior during fear conditioning (Kopec et al., 2007; Anagnostaras et al., 2010), home-cage phenotyping (Jhuang et al., 2010; Hübener et al., 2012; Balci et al., 2013), anxiety (Aarts et al., 2015), diurnal rhythms (Adamah-Biassi et al., 2013), and social behavior (Ohayon et al., 2013; Weissbrod et al., 2013; Hong et al., 2015). With feedback controlling components, automatic training systems have been successfully implemented in multiple behavioral domains, including memory assessment (Reiss et al., 2014), operant learning (Remmelink et al., 2015), and training limb function (Becker et al., 2016). Automatic training systems with multiple cognitive behaviors requiring memory, attention and decision making have been developed previously in free-moving rats (Erlich et al., 2011; Poddar et al., 2013) and mice (Romberg et al., 2013; Gallistel et al., 2014; Burgess et al., 2017). Moreover, such systems were successful in dissecting neural-circuitry mechanisms underlying cognitive behaviors (e.g., Erlich et al., 2011; Brunton et al., 2013; Hanks et al., 2015). Head-fixed mice (Dombeck et al., 2007; Guo et al., 2014) renders great flexibility in recording (Harvey et al., 2009; Boyd et al., 2012; Fukunaga et al., 2012; Kollo et al., 2014) and imaging (Dombeck et al., 2007; Komiyama et al., 2010; Boyd et al., 2015; Chu et al., 2016; Yamada et al., 2017) technologies. Moreover, free-moving and head-restrained mice exhibit similar ability of olfactory discrimination (Abraham et al., 2012). However, automatic training systems in head-fixed mice were not developed previously.

Olfaction is an important sensory modality for cognitive behavior (Doty, 1986; Ache and Young, 2005). Previous studies have demonstrated that rodents are very good at olfactory discrimination, memory, and decision (Passe and Walker, 1985; Slotnick et al., 1991; Lu et al., 1993; Mihalick et al., 2000; Hübener and Laska, 2001; Cleland et al., 2002; Petrulis and Eichenbaum, 2003; Uchida and Mainen, 2003; Abraham et al., 2004; Rinberg et al., 2006; Kepecs et al., 2007; Barnes et al., 2008; Komiyama et al., 2010; Haddad et al., 2013; Liu et al., 2014). Automatic behavioral systems have been developed for studying innate olfactory behaviors (Qiu et al., 2014). Olfactory behavioral testing has been developed in head-fixed rodents and greatly facilitates the understanding of neural circuits underlying olfaction (Verhagen et al., 2007; Wesson et al., 2008; Shusterman et al., 2011; Kato et al., 2013; Boyd et al., 2015) and odor-based cognition (Komiyama et al., 2010; Liu et al., 2014; Gadziola et al., 2015). However, fully automatic training systems for odor-based cognitive behaviors were not available for head-fixed mice.

We therefore designed a high-throughput automatic training system (HATS) for olfactory behaviors in head-fixed mice. Using the automatic step-by-step training procedures, we trained mice to perform olfactory delayed non-match to sample (DNMS), delayed paired association (DPA), Go/No-go (GNG) and GNG reversal tasks. Mice reached stable levels of performance within several days in the tasks. HATS can be an important tool in our understanding of the neural-circuitry mechanisms underlying odor-based cognitive behaviors.

\section{MATERIALS AND METHODS}

\section{Animals}

Male adult C57BL/6 mice (SLAC, as wild-type) were used for the current study (8-40 weeks of age, weighted between $20 \mathrm{~g}$ and $30 \mathrm{~g}$ ). Wild-type mice were provided by the Shanghai Laboratory Animal Center (SLAC), Chinese Academy of Sciences (CAS), Shanghai, China. Mice were group-housed (4-6/cage) under a 12-h light-dark cycle (light on from 5 a.m. to 5 p.m.). Before behavioral training, mice were housed in stable conditions with food and water ad libitum. After the start of behavioral training, the water supply was restricted. Mice could drink water only during and immediately after training. Care was taken to keep mice body weight above $80 \%$ of a normal level. The behavioral results reported here were collected from a total of 25 wild-type mice. All animal studies and experimental procedures were approved by the Animal Care and Use Committee of the Institute of Neuroscience, Chinese Academy of Sciences, Shanghai, China.

\section{Animal Surgery}

Mice were anesthetized with analgesics (Sodium pentobarbital, $10 \mathrm{mg} / \mathrm{mL}, 80 \mathrm{mg} / \mathrm{kg}$ body weight) before surgery. All surgery tools, materials and experimenter-coats were sterilized by autoclaving. Surgery area and materials that cannot undergo autoclaving were sterilized by ultraviolet radiation for more than $20 \mathrm{~min}$. Aseptic procedures were applied during surgery. Anesthetized mice were kept on a heat mat to maintain normal body temperature. Scalp, periosteum and other associated soft tissue over skull were removed. Skull was cleaned by filtered artificial cerebrospinal fluid (ACSF) with cotton applicators. After skull was dried out, a layer of tissue adhesive was applied on the surface of the skull. A steel plate was placed on the skull and then fixed by dental Cement.

\section{Behavior Setups}

HATS was composed of a mouse containing, head-fix, odor delivery and reward delivery, Arduino based control and data acquisition units (diagram in Figure 1A, photo in Figure 1B). All valves and motors were controlled by Arduino based processors and customized software. The $3 \mathrm{~d}$ printing files, a step by step instruction for hardware assembling, the source code for behavior training and the data acquisition source code were publically available $e^{1,2}$

Three-dimensional printing technique was used to generate the small components in the system (Figure 1C). The training tube was used to maintain the relative position of mouse body to the water- and odor-delivery ports. The motor slot held a directcurrent motor to move the water port forward or backward. The water tube slot held a metal needle with a blunt tip, from which

\footnotetext{
${ }^{1}$ https://github.com/wwweagle/serialj

${ }^{2}$ https://github.com/jerryhanson/frontiers
} 


\section{A}

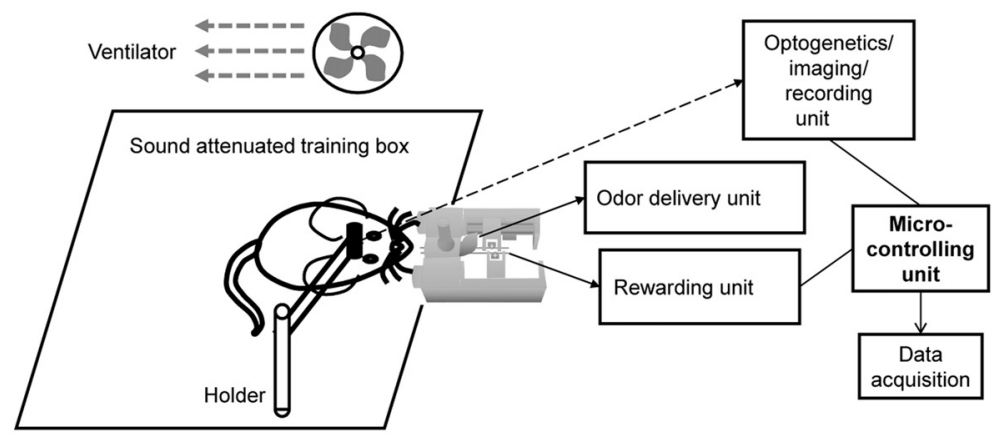

B

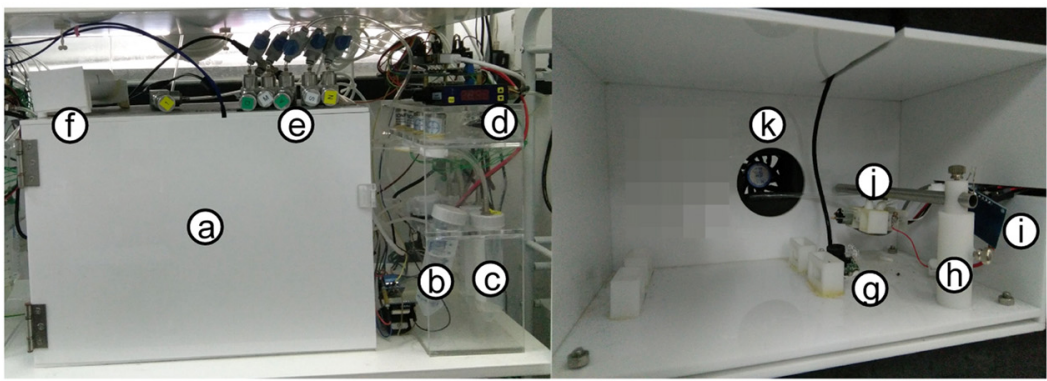

C

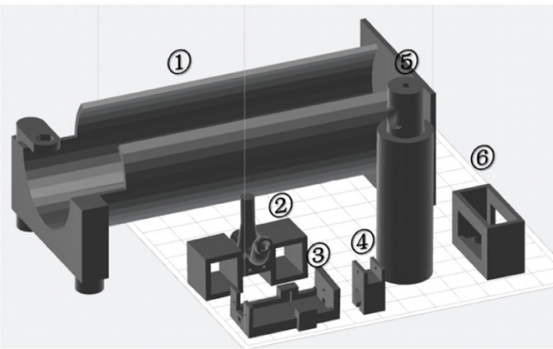

D

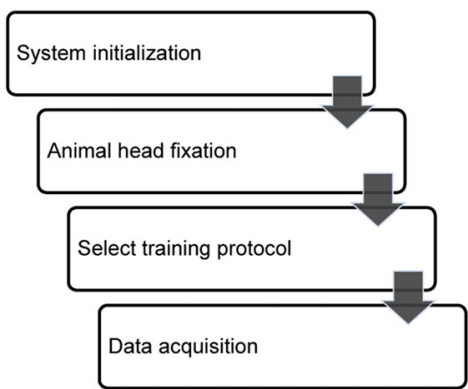

FIGURE 1 | Components and operational processes for high-throughput automatic training system (HATS). (A) Schematics showing the components of HATS. (B) Photos of HATS hardware. a, sound-attenuated box; b-c, odor containers; d, flow meter; e, needle valve; f, training tube for restraining mouse body; g, camera; h, holder for the odor- and water-delivery unit and motors; i, capacitance detector for licking; j, 3D-printed odor and water delivery unit; k, ventilator. (C) 3D-printed components. 1, mouse-body tube; 2, a socket for odor-delivery tubes; 3-4, slots for the motor of the moveable water port; 5, a holder for the odor- and water-delivery unit and motors; 6, a socket for the training tubes. (D) Schematics of the operational processes for HATS.

mice obtained water as a reward. The odor-tube slot connected the odor tube from the odor-delivery unit.

A movable water port was connected to a peristaltic pump, which was controlled by an Arduino board. The volume of water reward was controlled by changing the duration of the output signal to peristaltic pump from the Arduino board. Peristaltic pumps of different setups were calibrated for the stable volume of water delivery in each trial $(5 \pm 0.5 \mu \mathrm{L})$.

Water- and odor-delivery units were both controlled by an Arduino board. During behavior training, detailed timing information of events was sent back to the computer via the USB-simulated serial-port interface and stored by a customized Java program. The stored events included an odorant valve on/off, peristaltic pump on/off, and licking start/end. Licking event was detected by a capacity detector. Infrared LED-based licking detectors were used for electrophysiological recording if required. An infrared camera was placed under the water port to monitor behavioral states of mice.

\section{Olfactometer}

The olfactometer was designed to efficiently and reliably mix and deliver odor. Air source was a pump that provided air flow with the flow rate of $\sim 120 \mathrm{~L} / \mathrm{min}$. The filter was applied to eliminate moisture and dust. Eight training setups shared one set of pump and filter. For each setup, pure air with the flow rate of $2 \mathrm{~L} / \mathrm{min}$ is constantly delivered to mice during the entire process. The air input to each air route could be turned on 
A

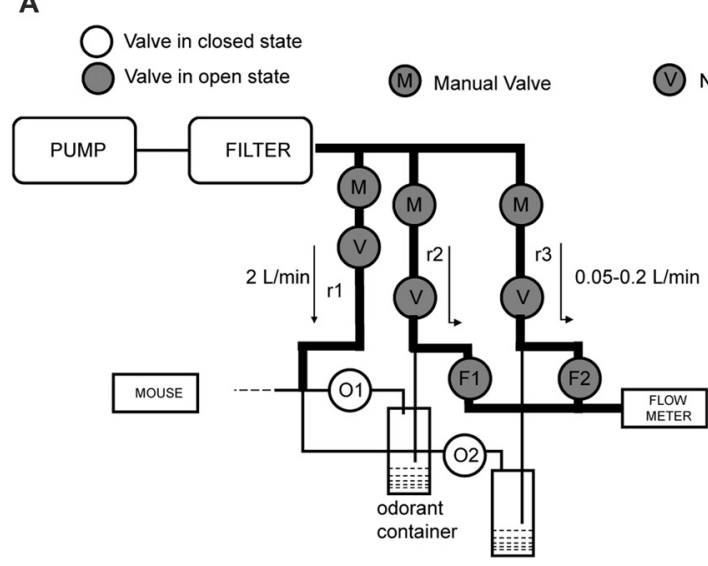

C

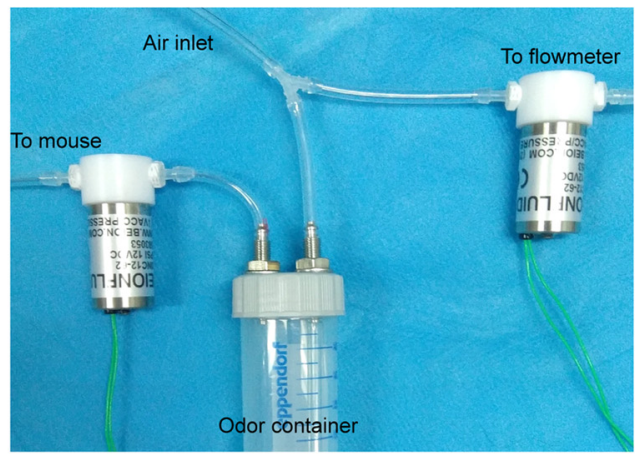

E

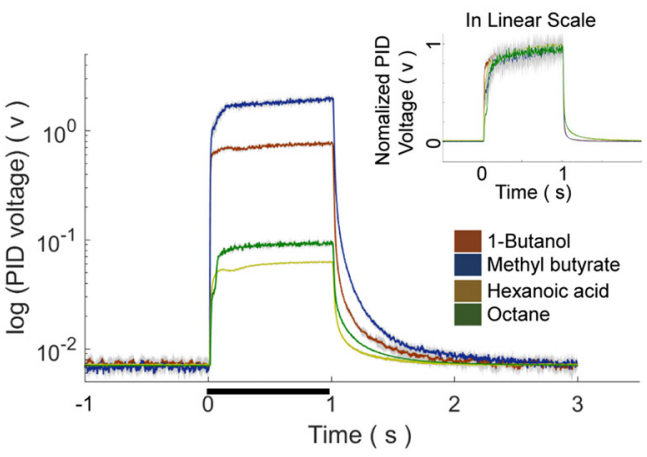

B

Needle valve (F) and mouse

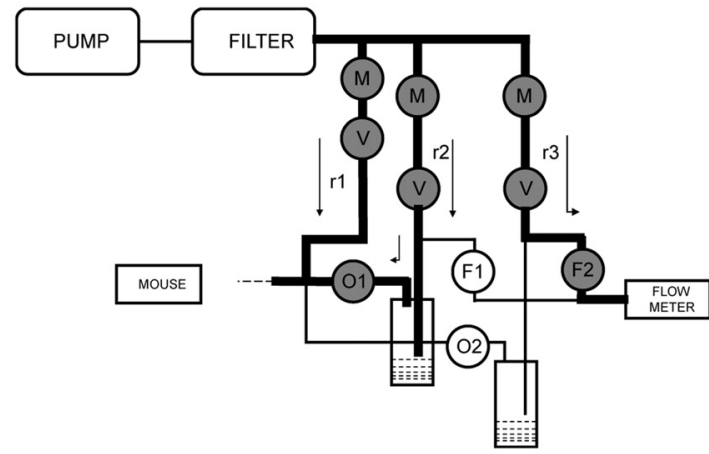

D

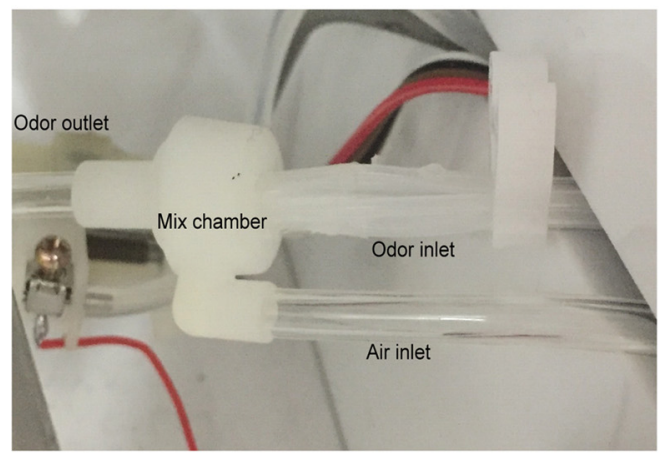

F

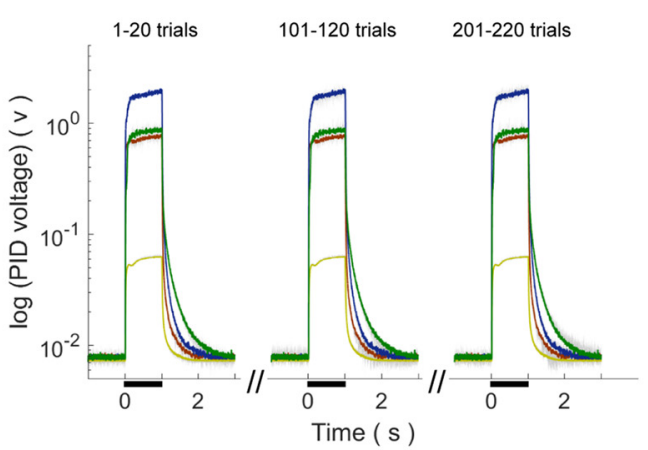

FIGURE 2 | Design, implementation and reaction time of the olfactometer. (A) Schematic showing the "standby" condition of the olfactometer. Diagram for the two-odor delivery unit was shown. The flow meter was designed for monitoring potential system failure. The flow rate was labeled as the numbers with the unit "L/min". Arrows indicated for the direction of air flow. (B) Schematic showing the "working" condition when one odor was delivered (through "r2"). Reduction of the readout from the flow meter indicated for normal operation. (C) Photo of the flow-controlling unit for the olfactometer. (D) Photo of the tubing unit and mixing chamber. Thin tubes were used for fast reaction for odor delivery. Mixing chamber was designed for a maximal mixture of pure air (from " $r 1$ " in B) and the delivered odor (from "r2" in B). (E) Fast response of the olfactometer. Readout from photoionization detector (PID) was plotted in the log scale for main figure and linear scale for inset (Mean \pm SEM, standard error of the Omean, unless stated otherwise; calculated from odor application of 200 trials). Rising/decay time constant and time with residual-odor were shown in Table 1. (F) Odor stability across trials.

and off by a manual valve (labeled as " $\mathrm{M}$ " in Figures 2A,B). The flow rate was adjusted by a needle valve (labeled as "V" in Figures 2A,B). As shown in the Figure 2B, one type of odorant in liquid state was stored in one airtight bottle. The air-in tube was placed right above the surface of the liquid odorant. Two-way solenoid valves were used to switch the odor to either mouse or flow mater. In the standby state (no odor was delivered, Figure 2A), the valve to odorant bottle (labeled as "O") was closed, and that to the flow meter (labeled as "F") was opened. Therefore, no odor will be mixed with pure air 
TABLE 1 | Rising and decay properties of odorants.

\begin{tabular}{lcc}
\hline Odorant name & Relative volume ratio in air (\%) & Rising latency (95\% of peak) \\
\hline 1-Butanol & 10 & $18 \pm 1$ \\
Methyl butyrate & 2.5 & $17 \pm 1$ \\
Hexanoic acid & 15 & $31 \pm 1$ \\
Octane & 5 & $71 \pm 1$
\end{tabular}

Time was in a millisecond. Mean \pm standard error of the mean.

and delivered to the mouse. In the working state that odor was delivered (Figure 2B), "O" was open and "F" was closed. Therefore odor was mixed with constant air and delivered to the mouse. Four kinds of odorants were used in the behavior tasks, 1-Butanol, Methyl butyrate, Hexanoic acid and Octane. The relative volume ratios of these odorants in the pure air were $10 \%, 2.5 \%, 15 \%$ and $5 \%$, respectively. The difference was due to the distinct evaporation pressure of different odorant molecules at room temperature (see Table $\mathbf{1}$ for detailed rising/decay and residual time of the odorants). The odor tubes after "O" valves and before mixture chamber had an inner diameter of $0.5 \mathrm{~mm}$. The odor tube for constant air before mixture chamber had an inner diameter of $2.5 \mathrm{~mm}$.

\section{Behavior Training}

\section{Water Restriction}

Mice were allowed at least 7 days for recovery after surgery for head-plate implantation. Before the start of formal training, mice were water restricted for $48-72 \mathrm{~h}$, in which licking for water was allowed (less than $1.0 \mathrm{~mL}$ per day, exact amount was not monitored). Throughout the training, the daily intake of water was at least $0.6 \mathrm{~mL}$ per day (as in Guo et al., 2014) and typically $1.0 \mathrm{~mL}$ per day. Body weight was closely monitored and a steady increase in body was observed after initial decrease following $24 \mathrm{~h}$ restriction.

\section{Habituation Phases}

The habituation phase started $30 \mathrm{~min}$ before the start of the training phase and only occurred once. A training tube was placed into the home cage. Mice could explore the tube freely to be familiar with it. This step was designed to decrease the stress level of mice on the first day.

\section{Automatic Licking Teaching Phase}

This phase was designed to teach mice to lick freely from the water tube. A mouse was fixated on the head plate to a holding bar connected to the training tube. The animals were transferred from home cages to the apparatus and head fixed manually by experimenters. The total time spent in transition was less than a minute. Then the training tube was placed into and fixated to sliding sockets in the sound-attenuated box (the typical decrease from background noise was $15 \mathrm{~dB}$ ). Initially, the tip of the water port was placed five millimeters away from the mouse mouth. By using a program-controlled movable water port, the initiation of a teaching bout was associated with the forward movement of the water port. During each day, this phase was divided into three bouts to facilitate the association between movement of

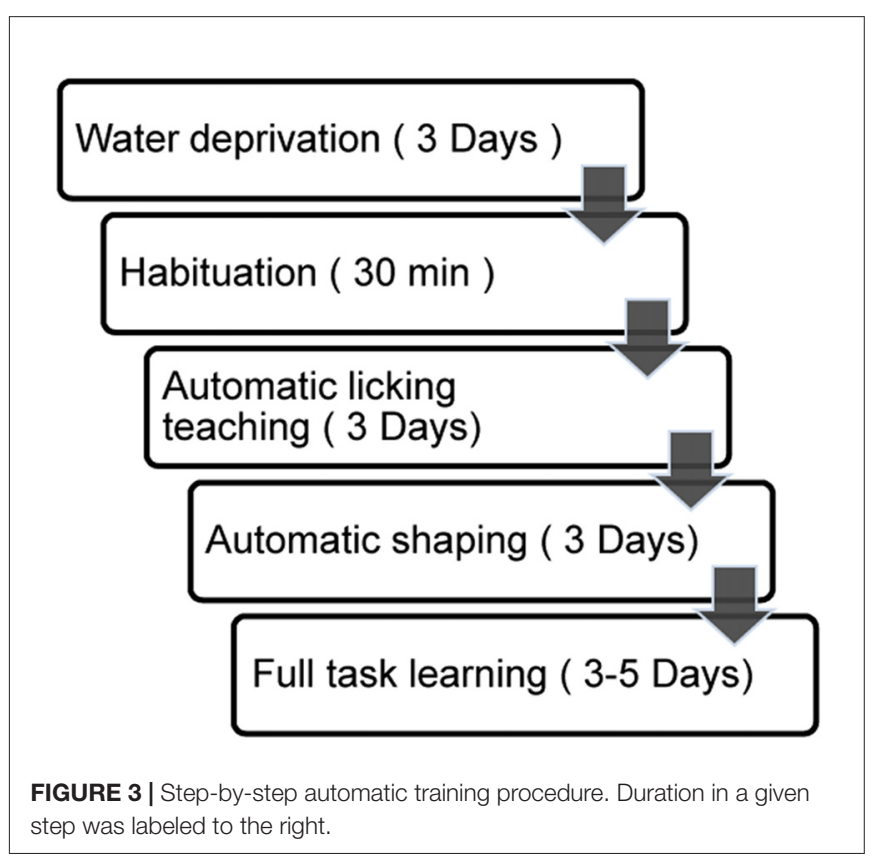

the water port and delivery of water. In each bout, water port moved forward firstly to seduce mouse to lick. After $2 \mathrm{~s}$, water port will be reset back to the original place. Once mouse licked, one water drop (volume of $\sim 5 \mu \mathrm{L}$ ) was delivered for every three licks. This bout ended when mice did not lick continuously for $2 \mathrm{~s}$, or rewarded size is larger than $200 \mu \mathrm{L}$ from this bout. The daily reward size could vary between each mouse (typically $0.6 \mathrm{~mL}$ and less than $1.0 \mathrm{~mL}$ ). This phase lasted for 3 days. Mice stayed in training apparatus for 1-2 $\mathrm{h}$ per day in all training phases.

\section{Automatic Shaping Phase}

This phase was designed to teach mice to lick for water only in the response window, which was from $0.5 \mathrm{~s}$ to $1.5 \mathrm{~s}$ after the offset of the second odor delivery. Only rewarded condition was applied, which were non-matched pairs for DNMS task, paired odors for DPA task, or go cue for GNG task, respectively. Mice could lick in response window to trigger water reward from every trial. During this phase, water port may or may not move while water was delivered. If mice missed several trials, lick-teaching would resume, in which the water port was moved forward and water was delivered during the response window. The reward in lick-teaching was program-controlled and was not triggered by lick. Two types of trials were defined for this phase, the self-learning (Figure 5, left) and programteaching (Figure 5, right) trials, which switched automatically 

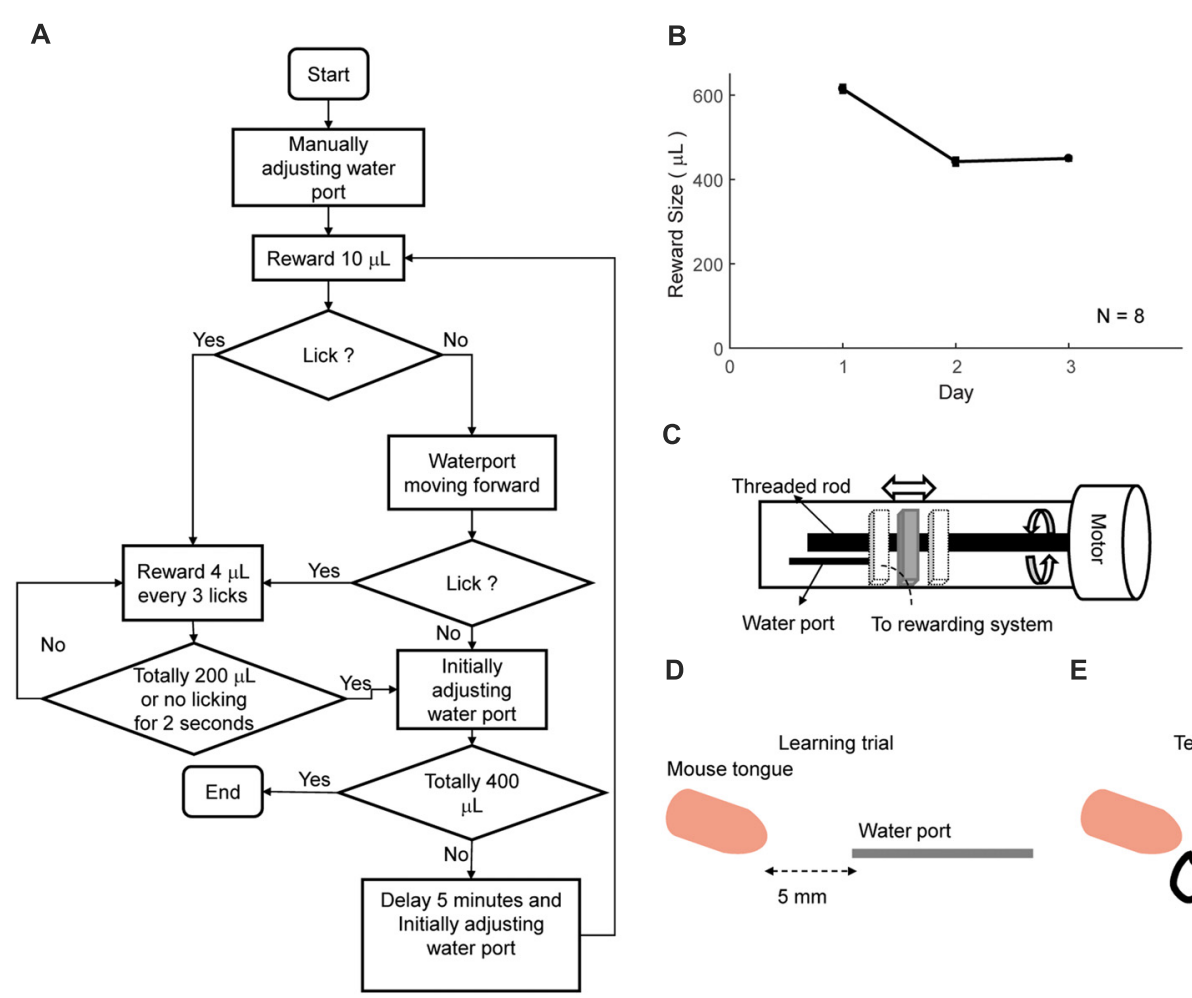

C

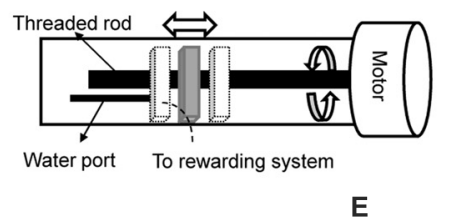

D

E
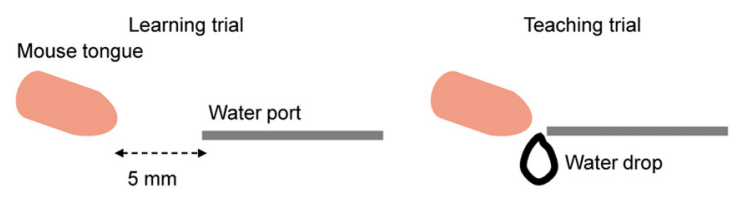

FIGURE 4 | Automatic lick-teaching protocol. (A) Flow chart for the automatic lick-teaching protocol. (B) Daily consumed water volume in the lick-teaching phase. (C) Diagram of the moveable water port. (D,E) Diagram showing relative position between water port and mouse mouth in self-learning (D) and teaching (E) phases.

under the condition introduced below. The water port was moved forward during the response window in the programteaching trials, in which the water delivery was automatic without triggered by licks. In the self-learning trials, however, reward delivery was licking-triggered, and water port did not move. The condition for switching from self-learning to programteaching trials was that mice missed five times within 30 trials or missed during the last program-teaching trial. The condition for switching from program-teaching trial to self-learning trial is that mice licked in response window and obtained a reward from the last teaching trial. Daily shaping phase ended when mice performed 100 hit trials in total. This phase lasted for 3 days.

\section{Full Task Training Phase DNMS task training}

In the DNMS task, a sample odor was delivered at the start of a trial, followed by a delay period (4-5 s) and then a test odor, same to (matched) or different from (non-matched) the sample (Figure 6). Two kinds of odorants were used in DNMS task, 1-Butanol, and Methyl butyrate. The relative volume ratios in the pure air were $10 \%$ and $2.5 \%$, respectively. Odor-delivery duration was $1 \mathrm{~s}$. Mice were trained to lick in the response window in non-match trials. The response window was from $0.5 \mathrm{~s}$ to $1.5 \mathrm{~s}$ after the offset of the second odor delivery. Licking events detected in the response window in the non-match trials were regarded as Hit and will trigger instantaneous water delivery (a water drop around $5 \mu \mathrm{L}$ ). The false choice was defined as detection of licking events in the response window in the match trials. Mice were not punished in the False Choice trials. Mice were neither punished nor rewarded for the Miss (no-lick in a non-match trial) or the Correct rejection (CR, no-lick in a matching trial) trials. Behavioral results were binned in blocks of 24 trials. There was a fixed inter-trial interval of $10 \mathrm{~s}$ between trials. After training ended each day, mice were supplied with water of at least $300 \mu \mathrm{L}$ and upto $1 \mathrm{~mL}$ daily intake. This phase lasts for 4-5 days. The well-trained criterion was set to the existence of three continuous correct-rates larger than $80 \%$, calculated using a sliding window of 24 trials. The reason to use 24 trials as a block is to maintain the consistency of different trial types between different tasks, with the need to be commonly divided by four and eight types of odor sequence for different tasks ( 4 for DNMS, 4 for DPA). It was intended to facilitate the comparison of the performance in the different tasks in the current study. It can be easily modified according to different needs.

\section{DPA task training}

For the DPA task, a sample and a test odor were delivered, separated by a delay period (Figure 7). Four kinds of odorants were used, 1-Butanol (S1), Methyl butyrate (S2), Hexanoic acid (T1) and Octane (T2). The relative volume ratios in pure air were $10 \%, 2.5 \%, 15 \%$ and $5 \%$, respectively. Odor delivery duration 
A

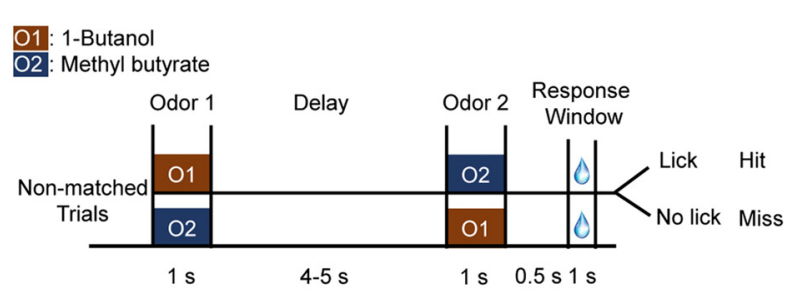

B

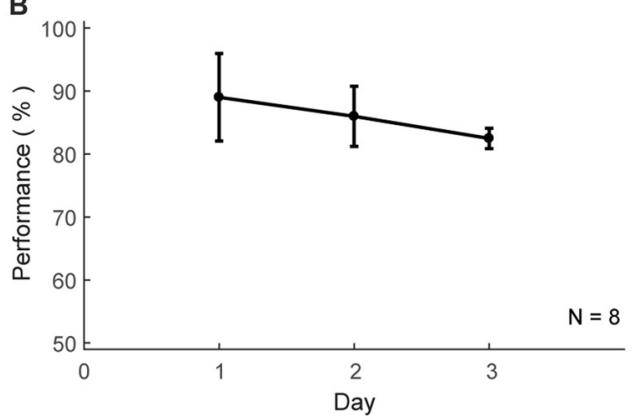

C

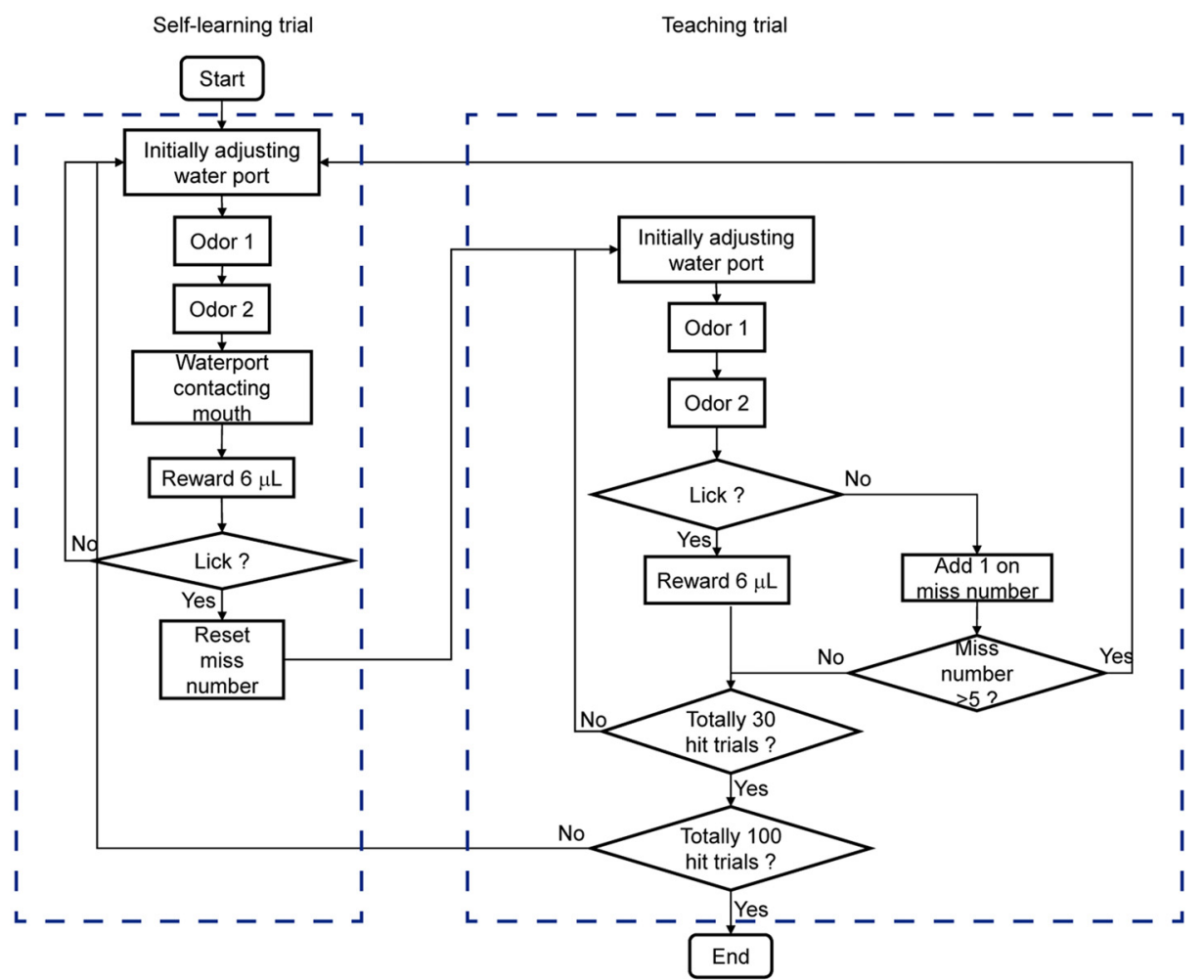

FIGURE 5 | Automatic shaping protocol. (A) Design paradigm and time line for the delayed non-match to sample (DNMS) shaping. Only non-matched trials were applied. (B) Licking performance in the shaping phase. (C) Flow chart for the DNMS shaping. Left: self-learning trials. Right: teaching trials.

was $1 \mathrm{~s}$. Delay period between two odors in a trial was 8-9 s. Response window was set to $0.5-1 \mathrm{~s}$ after the offset of the test odor in a trial. Mice were trained to lick to obtain water reward only after the paired trials (S1-T1 or S2-T2). Licking events detected in the response window in paired trials were regarded as Hit and will trigger instantaneous water delivery. The false choice was defined as detection of licking events in the response window in non-paired trials (S1-T2 or S2-T1), and mice were not punished in False Choice trials. Mice were neither punished nor rewarded for Miss (no-lick in the paired trial) or CR (no-lick in a non-paired trial) trials. Behavioral results were binned in blocks of 24 trials. There was a fixed inter-trial interval of $16 \mathrm{~s}$ between trials. After training ended each day, mice were supplied with water of at least $300 \mu \mathrm{L}$ and up to
$1 \mathrm{~mL}$ daily intake. This phase lasts for 4-5 days. The well-trained criterion was set to the existence of three continuous correctrates larger than $80 \%$, calculated using a sliding window of 24 trials.

\section{GNG and GNG reversal task training}

For the GNG task, mice were trained to lick for water only after the Go cue but not No-go cue. Hexanoic acid and Octane were used as Go and No-go cues, respectively. The relative volume ratios in the pure air were $15 \%$ and $5 \%$, respectively. Odor-delivery duration was $1 \mathrm{~s}$. Response window was $0.5-1.5 \mathrm{~s}$ after the offset of a cue. Licking events detected in the response window in Go trials were regarded as Hit and triggered instantaneous water delivery. The false choice was defined as 


\section{A}

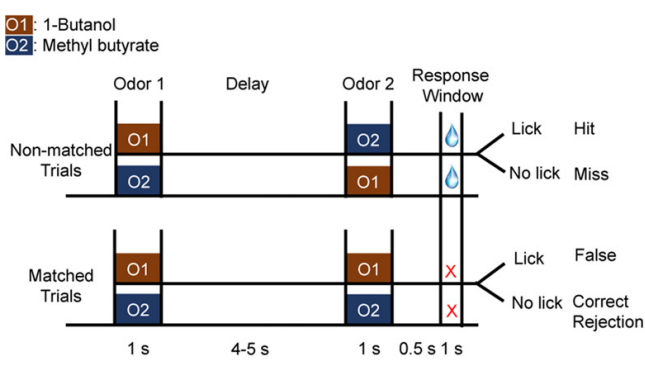

C

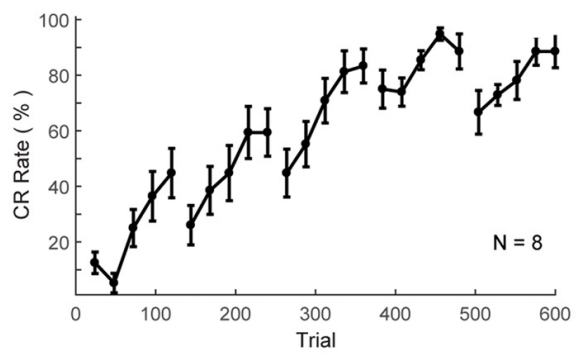

E

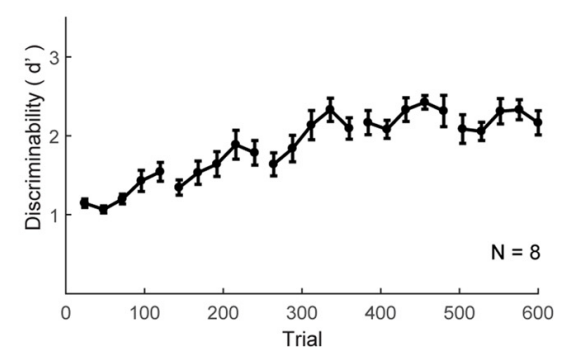

G

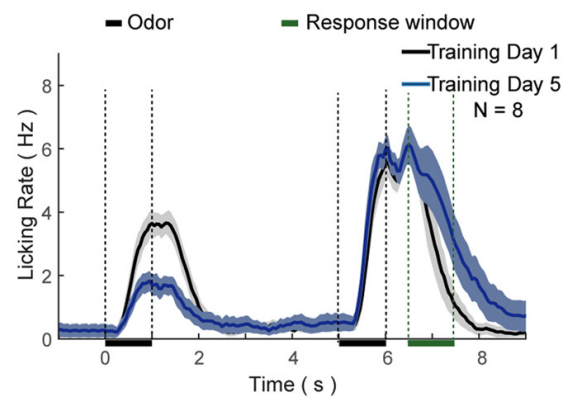

B

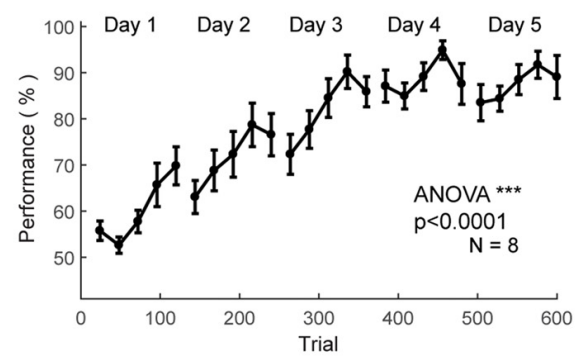

D

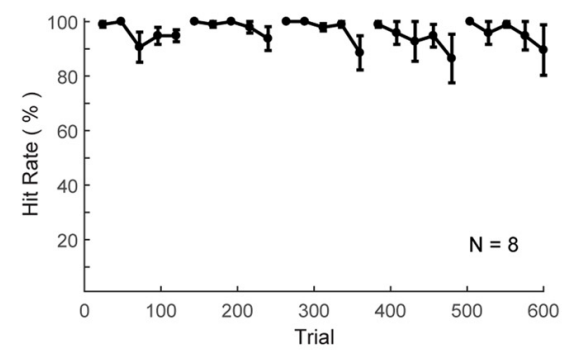

$\mathbf{F}$

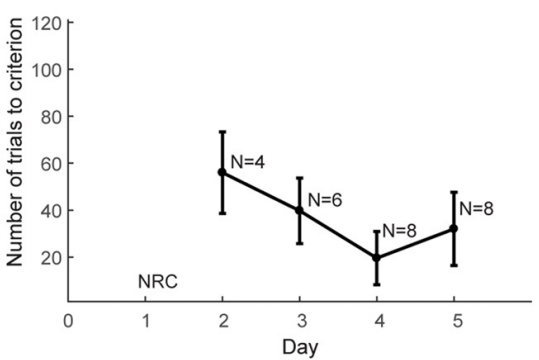

H

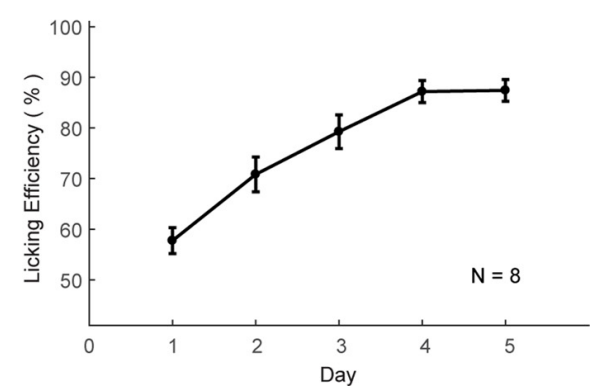

FIGURE 6 | Automatic DNMS training protocol and behavioral results. (A) Design paradigm and time line for the DNMS training. Both non-matched and matched trials were applied. (B) Performance of mice in the DNMS training phase. Bin size: 24 trials. (C-E) Correct rejection (CR) rate, hit rate and d' in the DNMS training, respectively. (F) Re-learning in each day of the DNMS training, measured by the number of trials to criterion (defined as more than $80 \%$ performance in 24 consecutive trials). NRC, not reaching criteria. Mice that were NRC in the 2nd and 3rd days were not included. (G) Licking rates for training day 1 and 5. (H) Licking efficiency in the DNMS training. Licking efficiency was defined as the ratio of successful licks resulting water reward.

the detection of licking events in the response window in No-go trials. Mice were not punished in the False Choice trials. Mice were neither punished nor rewarded for the Miss (no-lick in a Go trial) or the CR (no-lick in a No-go trial) trials. Behavioral results were binned in blocks of 24 trials. There was a fixed inter-trial interval of $5 \mathrm{~s}$ between trials. After training ended each day, mice were supplied with water of at least $300 \mu \mathrm{L}$ and up to $1 \mathrm{~mL}$ daily intake. This phase lasts for 3 days. The well-trained criterion was set to the existence of three continuous correct-rates larger than $80 \%$, calculated using a sliding window of 24 trials. 
A

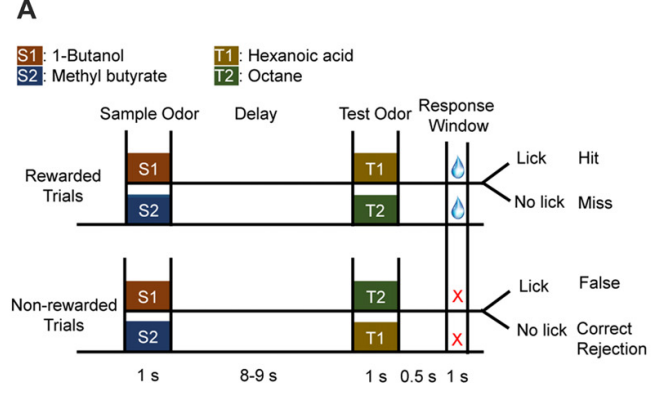

C

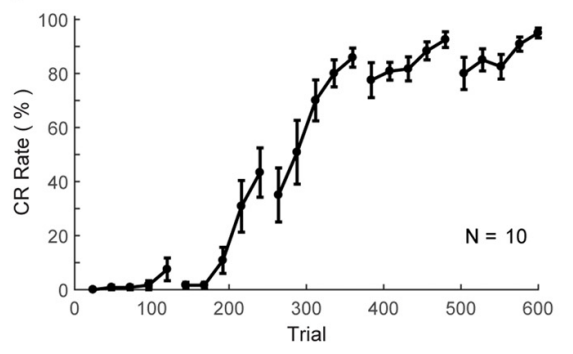

E

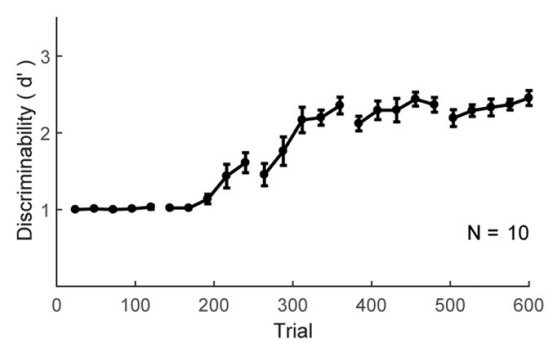

G

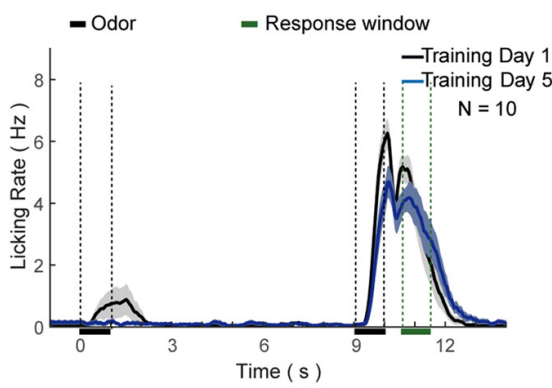

B

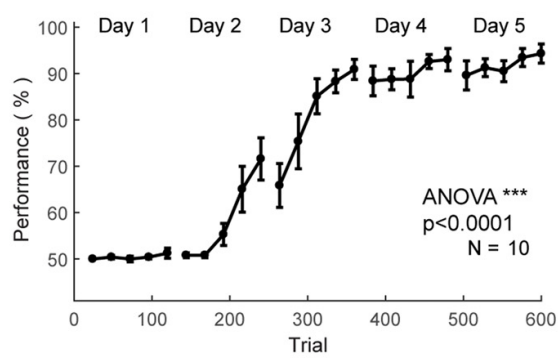

D

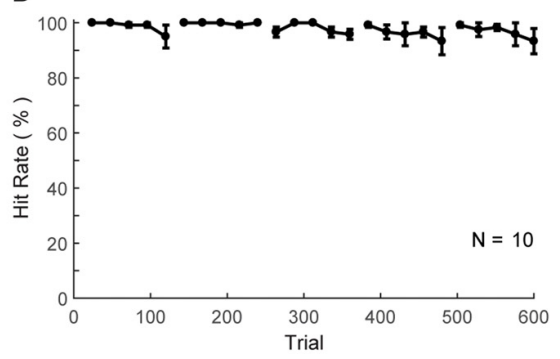

$\mathbf{F}$

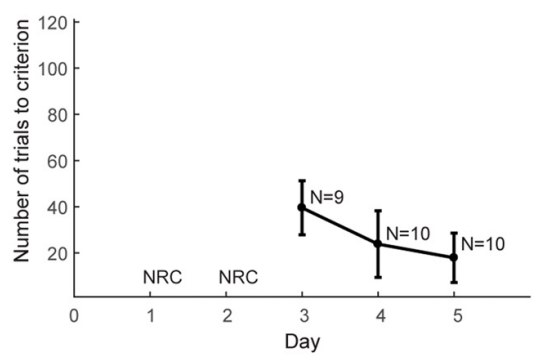

H

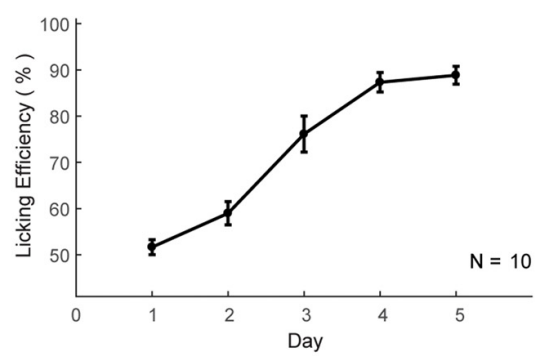

FIGURE 7 | Automatic delayed paired association (DPA) training protocol and behavioral results. (A-H) As in Figures 6A-H.

In the third day of training, the GNG reversal task began, in which the odor-reward relationship was reversed.

\section{Data Analysis}

The performance of the correct rate (referred to as "performance" in labels of figures) of each bin was defined by:

Performance correct rate $=$ (num. hit trials + num. correct rejection trials)/total number of trials
Hit, False choice and CR rates were defined as follows:

Hit rate $=$ num. hit trials $/$ (num. hit trials + num. miss trials)

False choice rate $=$ num. false choice trials/(num. false choice trials + num. correct rejection trials)

Correct rejection rate $=$ num. correct rejection trials/(num. false choice trials + num. correct rejection trials)

Mean correct rate ( $\mathrm{CR}$ rate/FA rate) was calculated as an averaged correct rate (CR rate/FA rate) between different mice. 
A

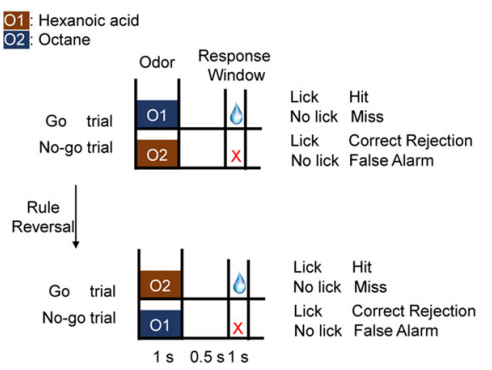

C

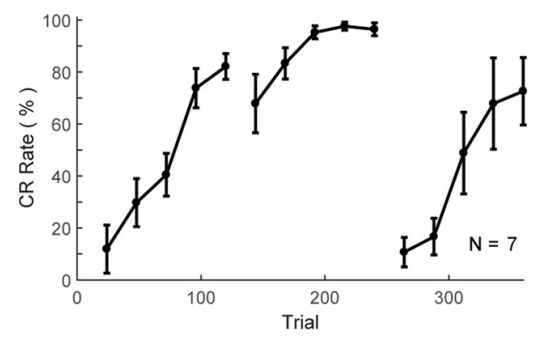

E

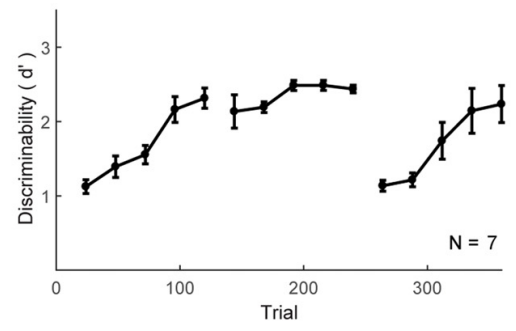

G

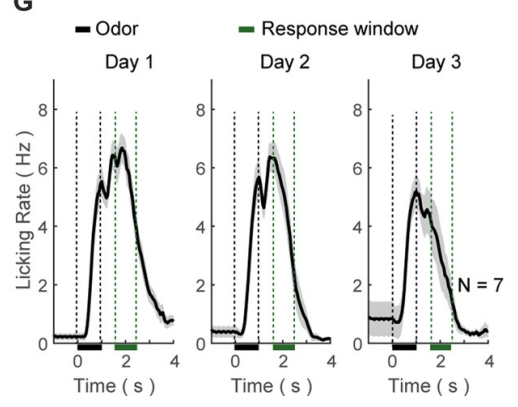

B

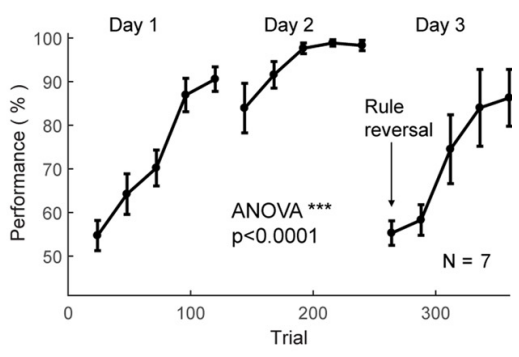

D

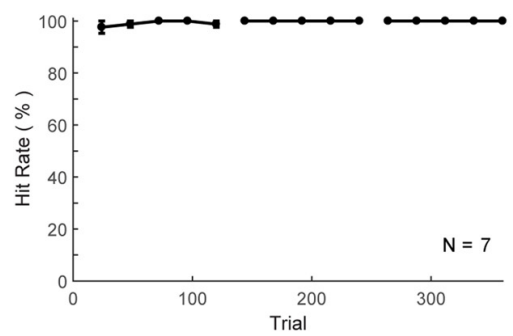

$\mathbf{F}$

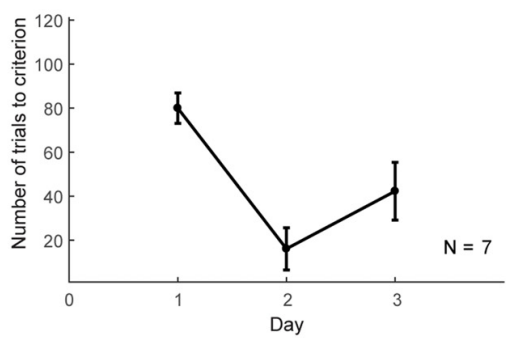

H

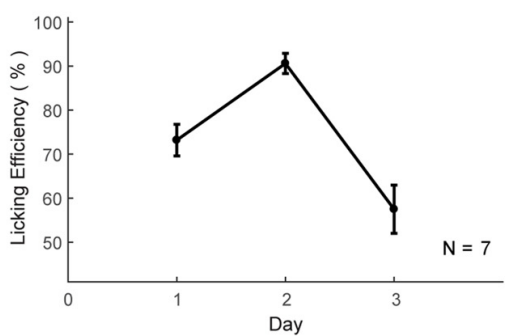

FIGURE 8 | Automatic Go/No-Go (GNG) and reversal training protocol and behavioral results. (A-H) As in Figures 6A-H.

Error bars from the mean value of the correct rate (CR rate/FA rate) was calculated by the standard error of the mean. $\mathrm{N}$ represents the number of mice.

The licking rate was calculated as lick numbers within each time bin (bin size: $100 \mathrm{~ms}$ ). The curve was smoothed by smooth function from Matlab with a span size of five bin.

Discriminability $\left(d^{\prime}\right)$ was defined by:

$d^{\prime}=$ norminv (Hit rate) - norminv (False choice rate). The norminv function was the inverse of the cumulative normal function. Conversion of Hit or False choice rate was applied to avoid plus or minus infinity (Macmillan and Creelman, 2005). In conversion, if Hit or False choice rate was equal to $100 \%$, it was set to $[1-1 /(2 n)]$. Here, $n$ equals to a number of all possible Hit or False choice trials. If Hit or False choice rate was zero, it was set to $1 /(2 \mathrm{n})$.

Licking efficiency $=$ rewarded licking number/(rewarded licking number + unrewarded licking number).

A number of trials to criterion was calculated as the trial numbers before reaching $80 \%$ correct rate for 24 consecutive trials. "NRC" in Figures 6-8 represented Not Reaching 
Criterion, which indicated that mice did not reach the above criterion for that day.

\section{RESULTS}

\section{Overview of Hardware, Software and Protocol}

In our previous study (Liu et al., 2014), mice were manually taught to lick for water and shaped for a DNMS task. The goal of the current study was to allow fully automatic training. The only things human operators need to perform were to fixate mice onto head-fix bars, close doors of training boxes, and run computer software controlling training protocols. The current study fulfilled the goal by designing HATS for olfactory and odor-based cognitive behavior in head-fixed mice. HATS was composed of a mouse containing, head-fix, odor- and water- delivery, Arduino based control, and data acquisition units (diagram in Figure 1A, photo in Figure 1B, 3D-printed parts in Figure 1C). Optogenetic, chemogenetic, recording, and imaging methods can be easily integrated into HATS. All valves and motors were controlled by Arduino based processors and customized software. The daily routine was composed of system adjustment, head-fixation of mice, choosing a protocol, and training mice a given behavior (Figure 1D).

\section{Fast Odor Delivery}

In studying olfactory behaviors, it is critical to have fast rise and decay for odor delivery.

Our olfactometer (Figures 2A-D) exhibited fast response and stable performance. The reaction time constant for the onset of these odors was between $11 \mathrm{~ms}$ and $71 \mathrm{~ms}$ (Table 1), measured with a photoionization detector (PID). Another key parameter was the time constant for decay after the offset of the odor-delivery unit, which was especially important in working memory-related tasks. The current odor-delivery unit exhibited fast decay (time constant: $20-41 \mathrm{~ms}$, Figure 2E, Table 1). Moreover, odor concentration remained stable following more than 200 trials of odor delivery (Figure 2F), which was important for behavioral and recording experiments.

\section{Automatic Training Protocol}

To achieve fully automatic training, we developed a step-bystep training protocol. The protocol was separated into two preparatory steps (water deprivation and habituation) and three training phases (lick-teaching, shaping and learning, Figure 3).

The first step of training was to automatically teach licking freely from water tube (Figures 4A,B). Moveable water port (Figures 4C-E) was located $5 \mathrm{~mm}$ away from the mouth of a mouse. The flow chart of the lick-teaching protocol was plotted in Figure 4A. At the start of a teaching bout, water port would deliver $10 \mu \mathrm{L}$ water and then moved forward until contacting the mouth, thus encouraging the licking. If mouse licked, $4 \mu \mathrm{L}$ water would be rewarded for every three licks. After no licking was detected for consecutive $2 \mathrm{~s}$ or water of $200 \mu \mathrm{L}$ was delivered, one bout of teaching was completed, and the water port was moved back to the initial position. The teaching bout was repeated for several times until water of $400 \mu \mathrm{L}$ was rewarded in total. The volume of water rewarded in each day was plotted in Figure 4B.

The second step of training was shaping for a specific task. This phase was designed to allow mice to be familiar with the temporal structure of the tasks and the involved sensory stimuli, without experiencing the full task. In shaping, only the trials with water reward were applied. Specifically, for DNMS task, only non-matched odor pairs were applied to mice (Figures 5A,B). For DPA task, only paired trials were applied. For GNG task, only Go cue was applied. Two types of trials were designed, self-learning and teaching trials. In self-learning trials, water delivery was triggered by licking in the response window (Figure 5C, left box). In teaching trials, water port moved forward and delivered water automatically during response window (Figure 5C, right box). These two types of trials were designed to switch automatically. The condition for switching from learning to teaching trial was that mice missed five trials in 35 trials. The condition for switching from teaching to learning trial was that mice licked within the response window in the last teaching trial. Daily shaping phase ended when mice performed 100 hit trials in total. This phase lasted for 3 days.

\section{Training the DNMS Task}

We trained eight head-fixed mice to perform an olfactory DNMS task (Liu et al., 2014; Figure 6A). In this design mouse needed to temporally maintain information during the delay period before behavioral choices and motor planning. After the shaping protocol, we added the non-rewarded matched trials, which induced false choice and reduced performance to chance level (Figure 6B). Gradually the performance, CR and discriminability $\left(d^{\prime}\right)$ progressively increased, whereas the hit rate remained at a ceiling level (Figures 6B-E). After the training of 5 days (600 trials), the performance showed significant increase (ANOVA, $p<0.0001, F=775.89$ ). Mice experienced a certain level of relearning each day, with a decreased number to criteria (defined as a correct rate above $80 \%$ in 24 consecutive trials) each day through learning (Figure 6F). Most of the licking responses were associated with non-match odor and expectation of water reward (Figure 6G). There were licks associated with the first odor delivery in the early phase of learning (Figure 6G, black curve), which were declined through learning (Figure 6G, blue curve). Also, the licking efficiency (defined as the ratio of successful licks resulting water reward) was increased progressively through learning (Figure 6H).

\section{Training the DPA Task}

The second set of head-fixed mice was trained to perform an olfactory DPA task (Figure 7A). As in the DNMS task, the performance, CR and discriminability $\left(d^{\prime}\right)$ progressively increased, whereas the hit rate remained at ceiling level (Figures 7B-E). After the training of 5 days (600 trials), the performance showed significant increase (ANOVA, $p<0.0001$, $F=1139.03$ ). Mice also experienced a certain level of relearning each day (Figure 7F). Most of the licking responses were associated with paired odor and expectation of water reward 
(Figure 7G). There were licks associated with the first odor delivery in the early phase of learning (Figure 7G, black curve), which were declined through learning (Figure 7G, blue curve). Such early licks associated with the sample odor were lower than that in the DNMS task. The licking efficiency also increased progressively through learning (Figure $7 \mathbf{H}$ ).

\section{Training the GNG and Reversal Tasks}

The third set of head-fixed mice was initially trained to perform an olfactory GNG task (Figure 8A, above), then subsequently sensory-cue reversal task (Figure $\mathbf{8 A}$, below). The performance, $\mathrm{CR}$ and discriminability $\left(d^{\prime}\right)$ progressively increased, whereas the hit rate remained at ceiling level (Figures 8B-E). After the training of 2 days (200 trials), the performance showed significant increase (ANOVA, $p<0.0001, F=3455.17$ ). Mice also experienced a certain level of relearning each day (Figure 8F). Most of the licking responses were associated with paired odor-pair and expectation of water reward (Figure 8G). The licking efficiency also increased progressively through learning (Figure 8H). After 2-days of GNG training, the odor-reward relationship was reversed (Figure 8A, below). The performance, CR, discriminability $\left(d^{\prime}\right)$ and licking efficiency were decreased initially, and then progressively increased (Figures 8B-E). The hit rate remained at ceiling level (Figure 8D) and relearning was evident from the number of trials to criteria (Figure 8F).

\section{DISCUSSION}

Automated, quantitative and accurate assessment of behaviors is critical for understanding mechanisms underlying cognition. Here we presented HATS, a new integrated hardware and software system that combined fast olfactometer, 3D-printed components, step-by-step automatic training, for automatic training of cognitive behaviors in head-fixed mice. The robustness of the system was validated in multiple olfactory and odor-based tasks. The involved tasks require cognitive abilities including working memory (Fuster, 1997; Baddeley, 2012), decision making (Gold and Shadlen, 2007; Lee et al., 2012), and reversal of learnt rules (Bunge and Wallis, 2008), all of which are required in more naturalistic environment and vital for survival.

An obvious limitation is that free-moving mice cannot be trained with HATS. Another limitation is that HATS only monitor the lick as behavioral readouts, therefore is more suited for large-scale screening of optogenetic. Although the head-movement was restrained in the current design, one would like to monitor the muscles controlling head or chewing movement to further eliminate the potential artifacts in electrophysiological recording. To obtain deep understanding

\section{REFERENCES}

Aarts, E., Maroteaux, G., Loos, M., Koopmans, B., Kovačevic, J., Smit, A. B., et al. (2015). The light spot test: measuring anxiety in mice in an automated home-cage environment. Behav. Brain Res. 294, 123-130. doi: 10.1016/j.bbr. 2015.06.011 of neural circuit underlying these behavior, one would also like to integrate more monitoring systems for behavioral events, such as sniffing (Kepecs et al., 2007; Verhagen et al., 2007; Wesson et al., 2008; Shusterman et al., 2011; Deschenes et al., 2012; McAfee et al., 2016), pupil size (Reimer et al., 2014, 2016; McGinley et al., 2015; Vinck et al., 2015; Bushnell et al., 2016), and whisker movement (Orbach et al., 1985; Friedman et al., 2006; Birdwell et al., 2007; O'Connor et al., 2010; Deschenes et al., 2012; Petreanu et al., 2012; Moore et al., 2013).

In designing HATS, we tried to fasten the training history, therefore aiding the dissection of neural circuit. However, this fast training in animals would only sufficiently model fast learning in humans. Indeed, many human behaviors and human learning are slow in learning and require extensive training, such as fine motor skill (e.g., driving, playing piano) and sensory discrimination (e.g., wine tasting). Thus, automations achieved in HATS have limitations to what kinds of behavioral and neural processes are being effectively modeled.

Nevertheless, HATS allowed for rapid, automated training of cognitive behaviors across diverse experimental designs. Our approach can also support high-throughput behavioral screening. In summary, the newly developed HATS are well-suited for circuitry understanding of odor-based cognitive behavior.

\section{AUTHOR CONTRIBUTIONS}

$\mathrm{ZH}$ and CTL designed the system and experiments, analyzed the results, and wrote the manuscript. XZ wrote behavioral software and contributed to data analysis. JZ and YC helped to debug the behavioral system.

\section{ACKNOWLEDGMENTS}

The work was supported by the Strategic Priority Research Program of the Chinese Academy of Sciences (Grant No. XDB02020006), the Chinese 973 Program (2011CBA00406), the Instrument Developing Project of the Chinese Academy of Sciences (Grant No. YZ201540), the Key Research Project of Frontier Science of the Chinese Academy of Sciences (Grant No. QYZDB-SSW-SMC009), China-Netherlands CAS-NWO Programme: Joint Research Projects, The Future of Brain and Cognition (153D31KYSB20160106), the Key Project of Shanghai Science and Technology Commission (No. 15JC1400102, 16JC1400101), the National Science Foundation for Distinguished Young Scholars of China (31525010, to CTL), the General Program of Chinese National Science Foundation (31471049), the State Key Laboratory of Neuroscience, and CAS Hundreds of Talents Program (2010OHTP04, to CTL).
Abraham, N. M., Guerin, D., Bhaukaurally, K., and Carleton, A. (2012). Similar odor discrimination behavior in head-restrained and freely moving mice. PLoS One 7:e51789. doi: 10.1371/journal.pone. 0051789

Abraham, N. M., Spors, H., Carleton, A., Margrie, T. W., Kuner, T., and Schaefer, A. T. (2004). Maintaining accuracy at the expense of speed: stimulus 
similarity defines odor discrimination time in mice. Neuron 44, 865-876. doi: 10.1016/s0896-6273(04)00753-6

Ache, B. W., and Young, J. M. (2005). Olfaction: diverse species, conserved principles. Neuron 48, 417-430. doi: 10.1016/j.neuron.2005.10.022

Adamah-Biassi, E. B., Stepien, I., Hudson, R. L., and Dubocovich, M. L. (2013). Automated video analysis system reveals distinct diurnal behaviors in C57BL/6 and C3H/HeN mice. Behav. Brain Res. 243, 306-312. doi: 10.1016/j. bbr.2013.01.003

Anagnostaras, S. G., Wood, S. C., Shuman, T., Cai, D. J., Leduc, A. D., Zurn, K. R., et al. (2010). Automated assessment of pavlovian conditioned freezing and shock reactivity in mice using the video freeze system. Front. Behav. Neurosci. 4:158. doi: 10.3389/fnbeh.2010.00158

Armbruster, B. N., Li, X., Pausch, M. H., Herlitze, S., and Roth, B. L. (2007). Evolving the lock to fit the key to create a family of G protein-coupled receptors potently activated by an inert ligand. Proc. Natl. Acad. Sci. US A 104, 5163-5168. doi: 10.1073/pnas.0700293104

Baddeley, A. (2012). Working memory: theories, models, and controversies. Annu. Rev. Psychol. 63, 1-29. doi: 10.1146/annurev-psych-120710100422

Balci, F., Oakeshott, S., Shamy, J. L., El-Khodor, B. F., Filippov, I., Mushlin, R., et al. (2013). High-throughput automated phenotyping of two genetic mouse models of Huntington's disease. PLoS Curr. 5:ecurrents.hd.124aa0d16753f88215776fba102ceb29. doi: 10.1371/currents.hd. 124aa0d16753f88215776fba102ceb29

Barnes, D. C., Hofacer, R. D., Zaman, A. R., Rennaker, R. L., and Wilson, D. A. (2008). Olfactory perceptual stability and discrimination. Nat. Neurosci. 11, 1378-1380. doi: 10.1038/nn.2217

Becker, A. M., Meyers, E., Sloan, A., Rennaker, R., Kilgard, M., and Goldberg, M. P. (2016). An automated task for the training and assessment of distal forelimb function in a mouse model of ischemic stroke. J. Neurosci. Methods 258, 16-23. doi: 10.1016/j.jneumeth.2015.10.004

Benkner, B., Mutter, M., Ecke, G., and Münch, T. A. (2013). Characterizing visual performance in mice: an objective and automated system based on the optokinetic reflex. Behav. Neurosci. 127, 788-796. doi: 10.1037/a0033944

Birdwell, J. A., Solomon, J. H., Thajchayapong, M., Taylor, M. A., Cheely, M., Towal, R. B., et al. (2007). Biomechanical models for radial distance determination by the rat vibrissal system. J. Neurophysiol. 98, 2439-2455. doi: 10.1152/jn.00707.2006

Boyd, A. M., Kato, H. K., Komiyama, T., and Isaacson, J. S. (2015). Broadcasting of cortical activity to the olfactory bulb. Cell Rep. 10, 1032-1039. doi: 10.1016/j. celrep.2015.01.047

Boyd, A. M., Sturgill, J. F., Poo, C., and Isaacson, J. S. (2012). Cortical feedback control of olfactory bulb circuits. Neuron 76, 1161-1174. doi: 10.1016/j.neuron. 2012.10.020

Brunton, B. W., Botvinick, M. M., and Brody, C. D. (2013). Rats and humans can optimally accumulate evidence for decision-making. Science 340, 95-98. doi: 10.1126/science. 1233912

Bunge, S. A., and Wallis, J. D. (2008). Neuroscience of Rule-Guided Behavior. Oxford, New York, NY: Oxford University Press.

Burgess, C. P., Lak, A., Steinmetz, N. A., Zatka-Haas, P., Bai Reddy, C., Jacobs, E. A. K., et al. (2017). High-yield methods for accurate twoalternative visual psychophysics in head-fixed mice. Cell Rep. 20, 2513-2524. doi: 10.1016/j.celrep.2017.08.047

Bushnell, M., Umino, Y., and Solessio, E. (2016). A system to measure the pupil response to steady lights in freely behaving mice. J. Neurosci. Methods 273, 74-85. doi: 10.1016/j.jneumeth.2016.08.001

Chu, M. W., Li, W. L., and Komiyama, T. (2016). Balancing the robustness and efficiency of odor representations during learning. Neuron 92, 174-186. doi: 10.1016/j.neuron.2016.09.004

Cleland, T. A., Morse, A., Yue, E. L., and Linster, C. (2002). Behavioral models of odor similarity. Behav. Neurosci. 116, 222-231. doi: 10.1037/0735-7044.116. 2.222

Davidson, A. B., Davis, D. J., and Cook, L. (1971). A rapid automatic technique for generating operant key-press behavior in rats. J. Exp. Anal. Behav. 15, 123-127. doi: $10.1901 /$ jeab.1971.15-123

Deisseroth, K., and Schnitzer, M. J. (2013). Engineering approaches to illuminating brain structure and dynamics. Neuron 80, 568-577. doi: 10.1016/j.neuron.2013. 10.032
Deschenes, M., Moore, J., and Kleinfeld, D. (2012). Sniffing and whisking in rodents. Curr. Opin. Neurobiol. 22, 243-250. doi: 10.1016/j.conb.2011. 11.013

de Visser, L., van den Bos, R., and Spruijt, B. M. (2005). Automated home cage observations as a tool to measure the effects of wheel running on cage floor locomotion. Behav. Brain Res. 160, 382-388. doi: 10.1016/j.bbr.2004.12.004

Dombeck, D. A., Khabbaz, A. N., Collman, F., Adelman, T. L., and Tank, D. W. (2007). Imaging large-scale neural activity with cellular resolution in awake, mobile mice. Neuron 56, 43-57. doi: 10.1016/j.neuron.2007.08.003

Doty, R. L. (1986). Odor-guided behavior in mammals. Experientia 42, 257-271. doi: 10.1007/bf01942506

Erlich, J. C., Bialek, M., and Brody, C. D. (2011). A cortical substrate for memoryguided orienting in the rat. Neuron 72, 330-343. doi: 10.1016/j.neuron.2011. 07.010

Fenno, L., Yizhar, O., and Deisseroth, K. (2011). The development and application of optogenetics. Annu. Rev. Neurosci. 34, 389-412. doi: 10.1146/annurevneuro-061010-113817

Fernando, A. B., and Robbins, T. W. (2011). Animal models of neuropsychiatric disorders. Annu. Rev. Clin. Psychol. 7, 39-61. doi: 10.1146/annurev-clinpsy032210-104454

Friedman, W. A., Jones, L. M., Cramer, N. P., Kwegyir-Afful, E. E., Zeigler, H. P., and Keller, A. (2006). Anticipatory activity of motor cortex in relation to rhythmic whisking. J. Neurophysiol. 95, 1274-1277. doi: 10.1152/jn.00945.2005

Fukunaga, I., Berning, M., Kollo, M., Schmaltz, A., and Schaefer, A. T. (2012). Two distinct channels of olfactory bulb output. Neuron $75,320-329$. doi: 10.1016/j. neuron.2012.05.017

Fuster, J. M. (1997). The Prefrontal Cortex: Anatomy, Physiology, and Neuropsychology of the Frontal Lobe. Philadelphia, PA: Lippincott-Raven.

Gadziola, M. A., Tylicki, K. A., Christian, D. L., and Wesson, D. W. (2015). The olfactory tubercle encodes odor valence in behaving mice. J. Neurosci. 35, 4515-4527. doi: 10.1523/JNEUROSCI.4750-14.2015

Gallistel, C. R., Balci, F., Freestone, D., Kheifets, A., and King, A. (2014). Automated, quantitative cognitive/behavioral screening of mice: for genetics, pharmacology, animal cognition and undergraduate instruction. J. Vis. Exp. 84:e51047. doi: 10.3791/51047

Gold, J. I., and Shadlen, M. N. (2007). The neural basis of decision making. Annu. Rev. Neurosci. 30, 535-574. doi: 10.1146/annurev.neuro.29.051605.113038

Gomez-Marin, A., Paton, J. J., Kampff, A. R., Costa, R. M., and Mainen, Z. F. (2014). Big behavioral data: psychology, ethology and the foundations of neuroscience. Nat. Neurosci. 17, 1455-1462. doi: 10.1038/nn.3812

Götz, J., and Ittner, L. M. (2008). Animal models of Alzheimer's disease and frontotemporal dementia. Nat. Rev. Neurosci. 9, 532-544. doi: 10.1038/nrn2420

Guo, Z. V., Hires, S. A., Li, N., O'Connor, D. H., Komiyama, T., Ophir, E., et al. (2014). Procedures for behavioral experiments in head-fixed mice. PLoS One 9:e88678. doi: 10.1371/journal.pone.0088678

Haddad, R., Lanjuin, A., Madisen, L., Zeng, H., Murthy, V. N., and Uchida, N. (2013). Olfactory cortical neurons read out a relative time code in the olfactory bulb. Nat. Neurosci. 16, 949-957. doi: 10.1038/nn.3407

Hanks, T. D., Kopec, C. D., Brunton, B. W., Duan, C. A., Erlich, J. C., and Brody, C. D. (2015). Distinct relationships of parietal and prefrontal cortices to evidence accumulation. Nature 520, 220-223. doi: 10.1038/nature14066

Harvey, C. D., Collman, F., Dombeck, D. A., and Tank, D. W. (2009). Intracellular dynamics of hippocampal place cells during virtual navigation. Nature 461, 941-946. doi: 10.1038/nature08499

Hong, W., Kennedy, A., Burgos-Artizzu, X. P., Zelikowsky, M., Navonne, S. G., Perona, P., et al. (2015). Automated measurement of mouse social behaviors using depth sensing, video tracking and machine learning. Proc. Natl. Acad. Sci. U S A 112, E5351-E5360. doi: 10.1073/pnas.1515982112

Hübener, J., Casadei, N., Teismann, P., Seeliger, M. W., Björkqvist, M., von Hörsten, S., et al. (2012). Automated behavioral phenotyping reveals presymptomatic alterations in a SCA3 genetrap mouse model. J. Genet Genomics 39, 287-299. doi: 10.1016/j.jgg.2012.04.009

Hübener, F., and Laska, M. (2001). A two-choice discrimination method to assess olfactory performance in pigtailed macaques, Macaca nemestrina. Physiol. Behav. 72, 511-519. doi: 10.1016/s0031-9384(00)00447-9

Jhuang, H., Garrote, E., Mutch, J., Yu, X., Khilnani, V., Poggio, T., et al. (2010). Automated home-cage behavioural phenotyping of mice. Nat. Commun. 1:68 doi: $10.1038 /$ ncomms1064 
Kato, H. K., Gillet, S. N., Peters, A. J., Isaacson, J. S., and Komiyama, T. (2013). Parvalbumin-expressing interneurons linearly control olfactory bulb output. Neuron 80, 1218-1231. doi: 10.1016/j.neuron.2013.08.036

Kazdoba, T. M., Del Vecchio, R. A., and Hyde, L. A. (2007). Automated evaluation of sensitivity to foot shock in mice: inbred strain differences and pharmacological validation. Behav. Pharmacol. 18, 89-102. doi: 10.1097/fbp. 0b013e3280ae6c7c

Kepecs, A., Uchida, N., and Mainen, Z. F. (2007). Rapid and precise control of sniffing during olfactory discrimination in rats. J. Neurophysiol. 98, 205-213. doi: 10.1152/jn.00071.2007

Kollo, M., Schmaltz, A., Abdelhamid, M., Fukunaga, I., and Schaefer, A. T. (2014). 'Silent' mitral cells dominate odor responses in the olfactory bulb of awake mice. Nat. Neurosci. 17, 1313-1315. doi: 10.1038/nn.3768

Komiyama, T., Sato, T. R., O’Connor, D. H., Zhang, Y. X., Huber, D., Hooks, B. M., et al. (2010). Learning-related fine-scale specificity imaged in motor cortex circuits of behaving mice. Nature 464, 1182-1186. doi: 10.1038/nature 08897

Kopec, C. D., Kessels, H. W., Bush, D. E., Cain, C. K., LeDoux, J. E., and Malinow, R. (2007). A robust automated method to analyze rodent motion during fear conditioning. Neuropharmacology 52, 228-233. doi: 10.1016/j. neuropharm.2006.07.028

Kretschmer, F., Kretschmer, V., Kunze, V. P., and Kretzberg, J. (2013). OMR-arena: automated measurement and stimulation system to determine mouse visual thresholds based on optomotor responses. PLoS One 8:e78058. doi: 10.1371/journal.pone.0078058

Lee, D., Seo, H., and Jung, M. W. (2012). Neural basis of reinforcement learning and decision making. Annu. Rev. Neurosci. 35, 287-308. doi: 10.1146/annurevneuro-062111-150512

Liu, D., Gu, X., Zhu, J., Zhang, X., Han, Z., Yan, W., et al. (2014). Medial prefrontal activity during delay period contributes to learning of a working memory task. Science 346, 458-463. doi: 10.1126/science.1256573

Lu, X. C., Slotnick, B. M., and Silberberg, A. M. (1993). Odor matching and odor memory in the rat. Physiol. Behav. 53, 795-804. doi: 10.1016/00319384(93)90191-h

Macmillan, N. A., and Creelman, C. D. (2005). Detection Theory: A User's Guide. Mahwah, NJ: Lawrence Erlbaum Associates.

McAfee, S. S., Ogg, M. C., Ross, J. M., Liu, Y., Fletcher, M. L., and Heck, D. H. (2016). Minimally invasive highly precise monitoring of respiratory rhythm in the mouse using an epithelial temperature probe. J. Neurosci. Methods 263, 89-94. doi: 10.1016/j.jneumeth.2016.02.007

McGinley, M. J., Vinck, M., Reimer, J., Batista-Brito, R., Zagha, E., Cadwell, C. R., et al. (2015). Waking state: rapid variations modulate neural and behavioral responses. Neuron 87, 1143-1161. doi: 10.1016/j.neuron.2015.09.012

Mihalick, S. M., Langlois, J. C., Krienke, J. D., and Dube, W. V. (2000). An olfactory discrimination procedure for mice. J. Exp. Anal. Behav. 73, 305-318. doi: 10.1901/jeab.2000.73-305

Moore, J. D., Deschênes, M., Furuta, T., Huber, D., Smear, M. C., Demers, M., et al. (2013). Hierarchy of orofacial rhythms revealed through whisking and breathing. Nature 497, 205-210. doi: 10.1038/nature12076

Nestler, E. J., and Hyman, S. E. (2010). Animal models of neuropsychiatric disorders. Nat. Neurosci. 13, 1161-1169. doi: 10.1038/nn.2647

O'Connor, D. H., Clack, N. G., Huber, D., Komiyama, T., Myers, E. W., and Svoboda, K. (2010). Vibrissa-based object localization in head-fixed mice. J. Neurosci. 30, 1947-1967. doi: 10.1523/jneurosci.3762-09.2010

Ohayon, S., Avni, O., Taylor, A. L., Perona, P., and Roian Egnor, S. E. (2013). Automated multi-day tracking of marked mice for the analysis of social behaviour. J. Neurosci. Methods 219, 10-19. doi: 10.1016/j.jneumeth. 2013.05.013

Orbach, H. S., Cohen, L. B., and Grinvald, A. (1985). Optical mapping of electrical activity in rat somatosensory and visual cortex. J. Neurosci. 5, 1886-1895.

Passe, D. H., and Walker, J. C. (1985). Odor psychophysics in vertebrates. Neurosci. Biobehav. Rev. 9, 431-467. doi: 10.1016/0149-7634(85)90021-1

Petreanu, L., Gutnisky, D. A., Huber, D., Xu, N. L., O’Connor, D. H., Tian, L., et al. (2012). Activity in motor-sensory projections reveals distributed coding in somatosensation. Nature 489, 299-303. doi: 10.1038/nature11321

Petrulis, A., and Eichenbaum, H. (2003). "Olfactory memory," in Handbook of Olfaction and Gustation, 2nd Edn. ed. R. L. Doty (New York, NY: Marcel Dekker), 409-438.
Poddar, R., Kawai, R., and Ölveczky, B. P. (2013). A fully automated high-throughput training system for rodents. PLoS One 8:e83171. doi: 10.1371/journal.pone.0083171

Qiu, Q., Scott, A., Scheerer, H., Sapkota, N., Lee, D. K., Ma, L., et al. (2014). Automated analyses of innate olfactory behaviors in rodents. PLoS One 9:e93468. doi: 10.1371/journal.pone.0093468

Reimer, J., Froudarakis, E., Cadwell, C. R., Yatsenko, D., Denfield, G. H., and Tolias, A.S. (2014). Pupil fluctuations track fast switching of cortical states during quiet wakefulness. Neuron 84, 355-362. doi: 10.1016/j.neuron.2014.09.033

Reimer, J., McGinley, M. J., Liu, Y., Rodenkirch, C., Wang, Q., McCormick, D. A., et al. (2016). Pupil fluctuations track rapid changes in adrenergic and cholinergic activity in cortex. Nat. Commun. 7:13289. doi: 10.1038/ncomms13289

Reiss, D., Walter, O., Bourgoin, L., Kieffer, B. L., and Ouagazzal, A. M. (2014). New automated procedure to assess context recognition memory in mice. Psychopharmacology 231, 4337-4347. doi: 10.1007/s00213-014-3577-3

Remmelink, E., Loos, M., Koopmans, B., Aarts, E., van der Sluis, S., Smit, A. B., et al. (2015). A 1-night operant learning task without food-restriction differentiates among mouse strains in an automated home-cage environment. Behav. Brain Res. 283, 53-60. doi: 10.1016/j.bbr.2015.01.020

Rinberg, D., Koulakov, A., and Gelperin, A. (2006). Speed-accuracy tradeoff in olfaction. Neuron 51, 351-358. doi: 10.1016/j.neuron.2006.07.013

Romberg, C., Horner, A. E., Bussey, T. J., and Saksida, L. M. (2013). A touch screen-automated cognitive test battery reveals impaired attention, memory abnormalities and increased response inhibition in the TgCRND8 mouse model of Alzheimer's disease. Neurobiol. Aging 34, 731-744. doi: 10.1016/j. neurobiolaging.2012.08.006

Roughan, J. V., Wright-Williams, S. L., and Flecknell, P. A. (2009). Automated analysis of postoperative behaviour: assessment of Home Cage Scan as a novel method to rapidly identify pain and analgesic effects in mice. Lab. Anim. 43, 17-26. doi: 10.1258/la.2008.007156

Schaefer, A. T., and Claridge-Chang, A. (2012). The surveillance state of behavioral automation. Curr. Opin. Neurobiol. 22, 170-176. doi: 10.1016/j.conb.2011. 11.004

Shusterman, R., Smear, M. C., Koulakov, A. A., and Rinberg, D. (2011). Precise olfactory responses tile the sniff cycle. Nat. Neurosci. 14, 1039-1044. doi: $10.1038 / \mathrm{nn} .2877$

Slotnick, B. M., Kufera, A., and Silberberg, A. M. (1991). Olfactory learning and odor memory in the rat. Physiol. Behav. 50, 555-561. doi: 10.1016/00319384(91)90545-y

Uchida, N., and Mainen, Z. F. (2003). Speed and accuracy of olfactory discrimination in the rat. Nat. Neurosci. 6, 1224-1229. doi: 10.1038/nn1142

Verhagen, J. V., Wesson, D. W., Netoff, T. I., White, J. A., and Wachowiak, M. (2007). Sniffing controls an adaptive filter of sensory input to the olfactory bulb. Nat. Neurosci. 10, 631-639. doi: 10.1038/nn1892

Vinck, M., Batista-Brito, R., Knoblich, U., and Cardin, J. A. (2015). Arousal and locomotion make distinct contributions to cortical activity patterns and visual encoding. Neuron 86, 740-754. doi: 10.1016/j.neuron.2015.03.028

Weissbrod, A., Shapiro, A., Vasserman, G., Edry, L., Dayan, M., Yitzhaky, A., et al. (2013). Automated long-term tracking and social behavioural phenotyping of animal colonies within a semi-natural environment. Nat. Commun. 4:2018. doi: 10.1038/ncomms3018

Wesson, D. W., Carey, R. M., Verhagen, J. V., and Wachowiak, M. (2008). Rapid encoding and perception of novel odors in the rat. PLoS Biol. 6:e82. doi: 10.1371/journal.pbio.0060082

Yamada, Y., Bhaukaurally, K., Madarász, T. J., Pouget, A., Rodriguez, I., and Carleton, A. (2017). Context- and output layer-dependent long-term ensemble plasticity in a sensory circuit. Neuron 93, 1198.e5-1212.e5. doi: 10.1016/j. neuron.2017.02.006

Conflict of Interest Statement: Patents for automatic training system and olfactormeter have been be filed to State Intellectual Property Office of the P.R.C.

Copyright (c) 2018 Han, Zhang, Zhu, Chen and Li. This is an open-access article distributed under the terms of the Creative Commons Attribution License (CC BY). The use, distribution or reproduction in other forums is permitted, provided the original author(s) and the copyright owner are credited and that the original publication in this journal is cited, in accordance with accepted academic practice. No use, distribution or reproduction is permitted which does not comply with these terms. 